of chemistry at Aberdeen, William J. Matheson, an American who founded an entrance scholarship and a bursary for chemistry at St. Andrews, and Thomas Purdie, who was to succeed Heddle in the professorship.

Purdie's occupancy of the chair marked a turning point in the history of chemistry and in the history of the University of St. Andrews. In his inaugural address, he stressed the "high educational value" of research; he introduced the study of organic chemistry, and he succeeded in establishing a research laboratory, the first of its kind in Scotland. An uncle of Purdie's left him a large sum of money, which he used to build a laboratory, and he had the satisfaction of seeing his research school well established. Purdie was succeeded in 1909 by Sir James Irvine himself, who continued in the chair until 1920, when he became principal of the University. The next occupant was Sir Robert Robinson, who was followed in 1922 by Prof. John Read. Summing up, Sir James pointed out that the St. Andrews chair of chemistry had had six occupants, five of whom, including the present holder, were fellows of the Royal Society; it had trained sixteen professors and one Government chemist. Altogether, this is a notable record for a chair which has been functioning for just a hundred years.

\section{Health Conditions in Guatemala}

IN a recent message to the National Legislative Assembly, General Jorge Ubico, the president of Guatemala, gives the following details concerning health conditions in that country during 1939 . 324,031 treatments were given to 67,371 malaria patients, 85,407 persons were treated for intestinal parasites, 2,486 dysentery cases received 13,123 treatments, 4,073 onchocerciasis patients were treated, 64,640 treatments for venereal disease were administered and 250 women were given 7,725 examinations. There were mild epidemics of whooping cough, diphtheria, measles and typhoid fever. The country has seventeen departmental hospitals, which cared for 48,815 persons.

\section{Recent Earthquakes}

ON December 20, at about 2.30 a.m. local time, an earthquake shook a wide area in the north-eastern United States and south-eastern Canada. It is reported to have been felt by people for some forty-five seconds in parts of Massachusetts, Maine, Connecticut and Rhode Island, and for a shorter time and less severe in Long Island, New York and New Jersey. In Montreal thousands of residents were awakened by the rattling of loose objects such as crockery on shelves, but no damage or casualties are reported. Another shock affected the same area on the morning of December 24, but only minor damage was caused and no casualties are reported. It is anticipated that the United States Coast and Geodetic Survey and other seismologists in the United States and Canada will be examining both instrumental and macroseismic evidence of the shocks, and any report is awaited with interest.

Also on December 20 an earth tremor was reported to have been felt for several seconds in the lower valley of the Arno River near Florence in Italy. Two earthquake shocks rocked the Erzinjan district of Turkey in the early hours of December 25, according to a message from Ankara. No damage or casualties are reported. The great Turkish earthquake in the same district occurred at 1.57 a.m. local time on December 27, 1939 (NATURE, January 6, 1940).

\section{Comet Cunningham}

A short notice about this comet was published in NatuRe of November 2 (p. 587). More recent observations have enabled $\mathrm{Mr}$. Cunningham to compute a better orbit, the elements of which are given below :

$\left.\begin{array}{lllrl}T & \ldots & \ldots & 1941 \text { Jan } & 16.25204 \\ \omega & \ldots & . & 199^{\circ} & 35 \cdot 5^{\prime} \\ \Omega & \ldots & \ldots & 295 & 42 \cdot 2 \\ i & \ldots & . & 49 & 51 \cdot 8\end{array}\right\} 1940 \cdot 0$

An ephemeris is given, commencing January 2. The comet is moving rapidly southwards, and after January 10 it will be too close to the sun to be observable. On January 6 it will be near `Aquilæ and should be easily visible to the naked eye.

\begin{tabular}{|c|c|c|c|c|}
\hline Jan. 2 & $\begin{array}{c}\text { R.A. } \\
19 \mathrm{~h} . \quad 35 \cdot 3 \mathrm{~m} .\end{array}$ & $\begin{array}{l}\text { Dec. } \\
+5^{\circ} 54^{\prime}\end{array}$ & $\begin{array}{c}\varrho \\
0.67\end{array}$ & $\begin{array}{c}r \\
0.54\end{array}$ \\
\hline , 6 & , $\quad 34 \cdot 3$ & $-2 \quad 19$ & 0.62 & 0.47 \\
\hline, 10 & $31 \cdot 5$ & 12 & 0.59 & 0.41 \\
\hline
\end{tabular}

\section{Announcements}

M. Henri Bergson, the celebrated philosopher, has refused to be exempted from the clauses of the new statute relating to Jews in France. The exemption was offered him for "exceptional services rendered to literature, science and art". He will therefore have to resign his chair at the Collège de France.

Prof. Robert D. Defries has been appointed director of the School of Hygiene and of the Connaught Laboratories, University of Toronto. During the past twenty-five years he has been prominent in the work of these two institutes, having early in 1915 become actively associated with the late Prof. J. G. FitzGerald, whom he now succeeds.

IN Administrative Memorandum No. 255 the Board of Education refers to the considerable risk of fire due to breaking of bottles containing dangerous chemicals in the event of a school being bombed. Those responsible should take precautions to minimize the risk. Only the smallest quantities of those chemicals, in particular, sodium, potassium, phosphorus, ether and strong acids, should be kept in the building and they should be stored in metal containers. 